\title{
INMIGRACIÓN Y DISCRIMINACIÓN: MECANISMOS SOCIOCOGNOSCITIVOS GENERADORES DE COMPORTAMIENTOS DISCRIMINATORIOS EN LOS ESTADOS UNIDOS
}

\author{
Rafael Arriaga Martínez
}

Resumen: Elucidar los mecanismos sociales y cognoscitivos que a nuestro juicio explican los prejuicios raciales y los comportamientos discriminatorios que han o siguen afectando la estructura de la relación de la sociedad dominante con los inmigrantes. Consideramos el caso de los europeos de cultura católica que llegaron a los Estados Unidos a lo largo del siglo XIX. Aplicamos las categorías de análisis propias a la Teoría General de la Racionalidad y esperamos contribuir al conocimiento del fenómeno de la discriminación de los inmigrantes $y$ - a través de un estudio comparativo ulterior-el relativo al de los inmigrantes mexicanos que, como en el caso de los europeos católicos, son percibidos como portadores de culturas incompatibles con la de la sociedad receptora.

Palabras clave: inmigración, discriminación, percepción, cultura, religión, católicos, protestantes, racionalidad cognoscitiva, racionalidad axiológica, racionalidad religiosa.

Enviado a dictamen: 11 de julio de 2009

Aprobación: 08 de septiembre de 2009

Revisiones: 1

Rafael Arriaga Martínez, doctor en Ciencias Sociales por la Universidad de Sorbonne-Paris (IV), temas de especialización: estudios culturales a partir de la teoría de la racionalidad de Max Weber y Raymond Boudon: formación e impacto de los valores culturales en los comportamientos económicos, sociales y de una manera general los procesos de estratificación social en los Estados Unidos. Correo electrónico: rarriaga@uabc.mx.
Abstract: To elucidate the social and cognitive mechanisms that we believe explain the racial prejudice and discriminatory behavior that have or continue to affect the structure of the relationship of the dominant society with immigrants. We consider the case of Catholic Europeans arriving to the United States throughout the nineteenth century. We apply the categories of analysis specific to the general theory of rationality and hope to contribute to the understanding of the phenomenon of discrimination against immigrants and in particular those pertaining to the Mexican immigrants as in the case of European Catholics whom are seen as bearers of cultural traits incompatible with the cultures of the host society

Key words: inmigration, discrimination, perception, culture, religion, catholics, protestants, cognitive ratiolity, axiologique rationality, religiouse rationality.

\section{Introducción}

$\mathrm{P}$ or mecanismos sociocognoscitivos, concepto fundamental de este artículo, entiéndase el proceso mental a través del cual los individuos suscriben los prejuicios y los comportamientos discriminatorios, afectando con ello la estructura de la relación entre la sociedad dominante y los inmigrantes. En esta comunicación trataremos, pues, de elucidar parcialmente 
estos mecanismos desde una perspectiva de origen y evolución en el tiempo, lo cual nos lleva a considerar el fenómeno de la inmigración y la percepción de ésta por parte de la sociedad dominante como la principal materia de análisis. Se trata de una perspectiva sociohistórica que atiende de manera particular el caso de los inmigrantes de cultura católica, originarios de Europa que llegan a los Estados Unidos a lo largo del siglo XIX.

Cabe advertir que esta comunicación es el resultado de un trabajo de investigación, cuyo desarrollo no sólo está en proceso sino que además forma parte de un estudio más vasto en donde comparamos la experiencia de los mexicanos con la experimentada por los inmigrantes originarios del Sur y del Este de Europa, siendo en ambos casos, grupos percibidos como portadores de culturas incompatibles con la de la sociedad receptora.

Que el estudio se refiera a unos u otros, en ambos casos nuestro objetivo es el mismo: elucidar los mecanismos sociales y cognoscitivos que a nuestro juicio explican los prejuicios raciales y los comportamientos discriminatorios que han o siguen afectando la estructura de la relación de la sociedad dominante con los inmigrantes.

\section{Racionalidad de las diferencias socioculturales}

De entrada, podríamos definir un comportamiento discriminatorio como el resultado de un razonamiento analítico que convendría definir como racionalidad cognoscitiva. Desde la perspectiva que ofrece la teoría de la racionalidad cognoscitiva de Raymond Boudon (2007), se dice que no todos los comportamientos se pueden explicar a partir del axiomático utilitario, y cuando esto sucede, es también posible que vaya entrelazado con elementos de tipo axiológico. Con esto queremos significar que si bien reconocemos la existencia de la utilidad económica, la ganancia como motivación, debemos igualmente aceptar que los comportamientos discriminatorios pueden también estar fundamentados en razonamientos analíticos nutridos de ideas y creencias acerca de los grupos humanos y las diferencias socioculturales que los caracterizan. En cuanto a las ideas y creencias acerca de las diferencias mencionadas - las que describen negativamente a los inmigrantes - éstas se forman a lo largo de un proceso en el que intervienen también derivaciones ideológicas, en el sentido de Vilfredo Pareto (1964).

Por derivaciones ideológicas entiéndase el procedimiento a través del cual los productores de ideologías -periodistas, intelectuales, pseudocientíficos- pulverizan los núcleos de teorías existentes - las relacionadas con las diferencias de cultura y comportamiento- para elevar sus proposiciones a estatus de verdades (cf. Boudon, 1998, 1999). ${ }^{1}$

Lo anterior es respecto a la oferta de ideas porque, por otra parte, están los consumidores de esas ideas y, lo que es más importante para nuestro análisis, los mecanismos sociales y cognoscitivos responsables de la adhesión del público a las mismas. Es de esta forma que surge nuestro interés por el estudio de las creencias colectivas como la mejor estrategia para avanzar en el conocimiento del problema que nos planteamos. Porque si hay una constante que surja de la reflexión acerca de las diferencias socioculturales entre los diferentes pueblos y que acompañe al pensamiento colectivo a través de toda su historia, esa sería la creencia en la superioridad cultural del pueblo estadounidense sobre los demás pueblos. Es esta convicción la que por mucho, estructura los comportamientos discriminatorios. Ahora bien, en lo que se refiere al origen en el tiempo de esta disposición cognoscitiva, ${ }^{2}$ tuvimos que abocarnos al estudio de la visión mesiánica de los colonos puritanos de la Nueva Inglaterra, en ella encontramos la idea de la elección providencial, la matriz de ese sentimiento de superioridad cultural (Arriaga, 2008), el cual a su vez favorece, como ya lo hemos dicho, la estructuración de los comportamientos discriminatorios.

Se trata de una idea - la de la superioridad cultural del pueblo estadounidense- que con el tiempo se despega de su matriz religiosa, difundiéndose a través 
de un proceso de racionalidad apoyado en un cuerpo de conocimiento cada vez menos religioso y cada vez más liberado de elementos metafísicos. A esto Weber lo define como desencanto del mundo (1959: 70). Así pues, vemos que la creencia en la superioridad moral o cultural del pueblo estadounidense atraviesa los siglos pulverizando núcleos de conocimiento retirados de la teología, de la filosofía, de las ciencias sociales para formar derivaciones ideológicas susceptibles de influir en la formación de opiniones con respecto a los inmigrantes y las diferencias que los caracterizan.

\section{Inmigración y discriminación}

De la historia de la inmigración a los Estados Unidos se puede, fácilmente y de manera clara, retirar la conclusión de que la discriminación no es un fenómeno nuevo y aun menos que éste haya afectado exclusivamente a los mexicanos. La mayoría de los inmigrantes que llegan a los Estados Unidos en olas sucesivas a lo largo del siglo XIX no solamente conocen la pobreza y la miseria durante al menos una generación sino que también fueron objeto de violencia y prácticas discriminatorias. Tal fue el caso de losinmigrantes católicos originarios de Alemania, Irlanda y, de una manera general, de Europa del Sur y del Este. Se dice que fueron globalmente veinticuatro millones de europeos que desembarcaron en los puertos de Estados Unidos entre 1821 y 1909 (Bureau of the Census, 1970).

Se piensa que la experiencia de los europeos de esta parte del hemisferio pudo haber sido menos ruda que la que conocieron los mexicanos en el siglo XX. Prueba de ello es, que entre los inmigrantes europeos y los estadounidenses sólo había diferencias de confesión porque, por el resto, aquellos eran blancos y originarios de Europa, semejantes a los estadounidenses. Sin embargo, la relación de los europeos con la sociedad dominante no dejó de ser conflictiva, si es que acaso no más conflictiva que la que experimentan los mexicanos de hoy en día. Porque las diferencias de confesión eran en esos tiempos percibidos a partir de una lógica muy distinta a la de nuestros tiempos. En efecto, la religión, la religión verdadera, como solían decir los viejos puritanos, era grosso modo percibida por el público como un vehículo ético portador de progreso económico y político. Es por eso que en esos tiempos se discutía acaloradamente acerca de la conveniencia de preservar la homogeneidad racial, religiosa y cultural de la sociedad estadounidense, con las consecuencias que ello implica para los inmigrantes portadores de culturas religiosas distintas. Para señalar la importancia del punto o la profundidad de la evolución axiológica que ha afectado a Estados Unidos y otros países confrontados a la inmigración, las políticas migratorias selectivas, apoyadas en supuestos cualitativos atribuidos a la raza, la cultura o la religión, o bien, son percibidas como aberraciones de otros tiempos o propias de países marginales.

\section{De la idea de la elección providencial a la idea de la superioridad cultural del protestantismo}

De que la religión que profesaban los estadounidenses en su mayoría fuera portadora de valores éticos favorables a la prosperidad general, era una convicción que el público respaldaba con "evidencias" que tenían que ver de una manera u otra con el progreso que venía experimentando la joven nación desde su fundación. Sin el éxito en los negocios, los puritanos con dificultad se hubiesen reconocido como los elegidos ante la providencia. Sin el crecimiento económico sorprendente que conocen las trece colonias, difícilmente el pueblo estadounidense de entonces, en su mayoría blancos protestantes y de ascendencia británica, o asimilada a ella, hubieran creído encarnar con sus valores el destino providencial del país. Sin expansión territorial, la que se extiende sobre el continente en detrimento de los pueblos nativos y el histórico norte de México, de nuevo, difícilmente los estadounidenses hubiesen creído en el destino manifiesto. Tales evidencias favorecieron también la creencia en la superioridad de su cultura religiosa frente a la de los inmigrantes católicos que 
llegaron masivamente durante el siglo XIX. Para los estadounidenses de hoy, que de una cierta manera experimentan la supremacía de los Estados Unidos sobre el mundo, la identidad religiosa ha dejado de ser un referente importante como para atribuirle a la cultura religiosa el origen de las diferencias entre las naciones. Ahora se trata de la superioridad a secas de un modelo de cultura y valores. Con esto reconocemos el postulado de la transubjetivización o la idea según la cual los individuos no suscriben a creencias o ideas no fundamentadas en evidencias. Se trata de una proposición respaldada en la teoría de la continuidad entre el pensamiento ordinario y el pensamiento científico, o la idea según la cual los individuos de la calle, por decir así, teorizan los problemas que les plantea la vida diaria (Boudon, 2003). Sin objetivización ${ }^{3}$ pues, las ideas como las creencias difícilmente se transubjetivizan, para expresarlo de acuerdo a una noción de Raymond Boudon.

Pues bien, esas evidencias de progreso y adelanto espectacular que el país experimentaba —en prácticamente todos los aspectos de la vida política, económica, social, científica, etcétera- - y que el público o la opinión pública del siglo XIX interpretaba de una manera monolítica, atribuyéndole el fenómeno a la cultura religiosa legada de la fe protestante, eran en los tiempos de los puritanos interpretadas como signos de elección providencial. ${ }^{4}$ Que los puritanos hayan interpretado ese progreso como signo de elección providencial, es algo que por lógica se desprende de su racionalidad religiosa y del dogma de la predestinación en particular (Weber, 1967). Dicho de otra manera, los puritanos interpretaban los datos de esa experiencia a partir del conocimiento que tenían de su doctrina religiosa. "Las religiones representan la primera forma de la explicación del mundo" observa Raymond Boudon (1998: 104).

Con la idea, pues, en la cabeza de la elección providencial, los puritanos no podían ver a los demás sino era desde una posición de superioridad moral, con todo lo que ello implica en términos relacionales. Se sabe, por ejemplo, que en virtud de la doctrina del imperativo de hacer todo para que la gloria de Dios fuera una realidad sobre la tierra, los puritanos de la Nueva Inglaterra controlaban los flujos migratorios en función de la pertenencia religiosa y el origen nacional. A través de esta restricción, que duró doscientos años, los puritanos lograron preservar la hegemonía religiosa y cultural de la colonia (Baltzell, 1979: 115).

Que el dogma de la predestinación haya participado en la génesis de los comportamientos discriminatorios en los Estados Unidos no es nada sorprendente en un país fundado sobre un proyecto de nación que le debe mucho a los ideales religiosos de los peregrinos, los primeros colonos puritanos de la Bahía de Massachusetts. Estamos hablando de un país en donde la religiosidad conserva desde entonces un lugar preponderante en la existencia de los individuos. Todas las encuestas y los sondeos de opinión lo confirman (cf. Inglehart y Moreno, 1998; Gallup, 2005, 2007).

La religión, en tanto que fuente interpretativa de las cosas de este mundo, ha perdido mucho de su monopolio con el tiempo. Muchas proposiciones de inspiración religiosas han sido eliminadas por otras proposiciones de carácter científico, pero ocurre que muchas de estas últimas proposiciones no llegan a ser admitidas plenamente cuando el hecho se muestra ante el público como una prueba empírica incontestable. La idea según la cual la tierra es redonda tomó mucho tiempo en ser aceptada por el público; el reconocimiento de este hecho gana su lugar en el mercado del conocimiento de las masas en la medida que las pruebas de su existencia se multiplicaban. De la misma manera, la idea de la superioridad cultural del protestantismo en relación al catolicismo cae en descrédito ante el público, pero ello ocurrió gradualmente; conforme los hechos confirmaban el ascenso social sostenido de los católicos de ascendencia europea, los descendientes de la ola migratoria percibida por el público de entonces como inasimilable. Finalmente, es el veredicto de la realidad el que se pronuncia a favor o contra una teoría, qué importa que ésta obedezca a los cánones de la ciencia o sea elaborada por el hombre ordinario de 
INMIGRACIÓN Y DISCRIMINACIÓN: MECANISMOS SOCIOCOGNOSCITIVOS

GENERADORES DE COMPORTAMIENTOS DISCRIMINATORIOS

EN Los Estados Unidos

acuerdo a los mecanismos cognoscitivos de la asociación de ideas (Boudon, 2000: 82). En Emile Durkheim Boudon se encuentra un enunciado que respalda lo anterior:

En el fondo, si los conceptos científicos inspiran confianza es porque éstos son susceptibles de ser controlados metódicamente. Ahora bien, una representación colectiva está necesariamente sometida a un control indefinidamente repetido, los hombres que las aceptan la verifican por su propia experiencia. Esta no podría estar completamente inadecuada a su objeto (Boudon, 2000: 82).

Boudon observa que la racionalidad del mundo opera con base a dos planos. Uno es el de la realidad y el otro el de la sensibilidad inherente al hombre, el sentido que los hombres le dan a los hechos sociales o naturales que observan en su entorno (Boudon, 1999: 200). Pero como la sensibilidad no puede ser la misma para todos, es de esperarse que no todos los individuos interpreten de la misma manera un mismo hecho, como ocurre entre un hombre de ciencia, de religión o portador de un conocimiento ordinario. Aunque hay épocas y sociedades en donde los individuos se muestran más receptivos a los argumentos interpretativos de uno u otro.

Consideramos, pues, un público activo desde el punto de vista cognositivo, preocupado por formarse una opinión sólida o una convicción personal en relación a los problemas colectivos. Lejos de conformarse con su propia convicción íntima, los individuos buscan confirmar y legitimizar sus creencias y sus valores. Esta necesidad facilita la escucha de las retóricas que más le puedan ser útiles. La teología fue en el pasado una fuente de derivaciones importante como lo es hoy la ciencia en relación a la ideología. Y es en ese sentido que, de acuerdo a una estimación de Boudon, Durkheim, establece una relación de continuidad entre la religión y la ciencia. La religión, de forma verosímil, desempeñaba una función análoga a la de la ciencia (Boudon, 2000: 82): la de interpretar el mundo.
Para Pareto, según Boudon, las derivaciones son un fenómeno universal que se encuentra en todas las etapas del pensamiento humano, siendo la ideología sólo una expresion específica, contemporánea del siglo XIX. Teólogos, filósofos, políticos y pseudocientificos, cada uno de ellos juega o jugó, según las épocas, un papel importante en tanto que produjeron pseudodemostraciones. Ahora bien, el siglo XIX es el siglo de la ciencia, de la santa ciencia, como diria Pareto (cf. Boudon, 1998: 224, 225). Pero en Estados Unidos, a la diferencia de Europa, la ideología no tritura sólo nucleos científicos para hacer pasar sus proposiciones como verdades ante el público. Bajo forma directa o sublimada, amplias capas del público siguen manifestando su interés por las argumentaciones mesiánicas.

El sueño de los peregrinos, en cuanto al destino providencial de la Ciudad de Dios que ellos pretendían edificar en algún monte de la Bahía de Massachusetts, se deja sentir al paso de los siglos, con la doctrina del Destino Manifiesto, con la preocupación frente a los inmigrantes católicos y otros por preservar el fondo cultural anglosajón y protestante de la nación y aún en la manera como el pueblo estadounidense evoca desde los atentados a las torres de Nueva York la idea según la cual Dios protege a América (God bless América) (cf. Arriaga, 2009).

Se trata pues de una idea y una creencia que llega a afectar el conocimiento y por vía de consecuencia la actitud de los estadounidenses protestantes en su relación con otros grupos con culturas distintas. En términos de consecuencias, podríamos decir que la adhesión a esta idea complica el proceso de integración social y económica de los católicos y otros grupos etnoreligiosos a partir del momento que ésta favorece, por una parte, la creación de núcleos de oposición organizada en contra de los inmigrantes y, por otra, la aprobación de leyes de exclusión migratoria. En todo caso, esto es justo lo que sucedió con las leyes de exclusión e inmigración de 1882 y 1924 que afectaron a los chinos (Hsiang, 1992) y a los Europeos del Sur y del Este, respectivamente, sin hablar de las numerosas proposiciones de ley dirigidas en contra de los mexicanos a lo largo del siglo XX. 


\section{El anticatolicismo del movimiento nativista}

Los estadounidenses del periodo colonial tenían argumentos para generar una corriente de opinión contraria a los católicos. En la frontera, tanto en el Sur como en el Norte, se les denunciaba como posibles colaboradores de los enemigos de los Estados Unidos, en especial de los españoles y los franceses, por su catolicidad (cf. Billington, 1938: 7-17). No es sino a partir de la Revolución Francesa que el catolicismo es fuertemente descubierto como incompatible con la libertad civil y las instituciones democráticas. La percepción de las monarquías sostenidas por la tradición y el clero católico contribuía para que ellos mismos se observaran como el contraejemplo del catolicismo en su relación con la modernidad. Se trata de una percepción fundamentada en algo más que un puro sentimiento. Es una convicción sustentada en un argumento respaldado por los hechos. Esto quiere decir que los individuos, para creer en lo que creen, recurren a un procedimiento muy conocido en el mundo de la ciencia, el de la falsificación en el sentido de Karl Popper. Para Boudon (2003: 61) los individuos, sin quererlo conscientemente, utilizan el principio de la falsificación desde el momento que se preocupan porque la teoría que se formula respecto a un problema o fenómeno sea lo más congruente posible con la realidad o los datos de la realidad que observan. Se podría decir incidentemente que para Boudon no existe la discontinuidad entre el conocimiento ordinario y el conocimiento científico.

Veamos a continuación la actitud de un individuo —o de un actor típico ideal, ${ }^{5}$ si se quiere— que, como un teórico, se felicita de exhibir un nuevo hecho que vendría a confirmar su tesis: en 1820 estalla en Filadelfia un conflicto entre obispos y laicos de la diócesis. El conflicto pasa a los anales de la historia del catolicismo como trusteeism controversy. El laicado pretendía reservarse la prerrogativa de nombrar a sus sacerdotes, además del control de los asuntos de la parroquia, mientras que, la jerarquía los amenazaba con la excomunión, pero sin ningún resultado disuasivo. La controversia termina finalmente, gracias a una mediación del Vaticano en beneficio de la jerarquía eclesiástica. La opinión pública, en particular protestante, aprovecha el incidente para criticar el sistema organizacional de la Iglesia católica. La intervención del Papa en favor de la jerarquía fue expuesto por los medios de comunicación de la época como un atentado a la democracia de la congregación, como un acto derogatorio de la tradición, de losideales del país y del carácter del gobierno republicano. Para la satisfacción de los protestantes partidarios de una América sin católicos; el catolicismo, según este punto de vista, se revelaba como una religión "incompatible con la libertad de las instituciones políticas americanas" y un "peligro para los Estados Unidos" (cf. Billington, 1938:39-41).

A los ojos de los nativistas, toda toma de decisión sin participación del laicado era inconcebible desde el punto de vista del conocimiento que tenían de las funciones democráticas de sus instituciones religiosas, además de que acusaban a los católicos de obedecer más a Roma que a su propio país. ${ }^{6}$ Siendo la libertad de culto una garantía constitucional, el catolicismo como culto, no podía ser prohibido, es cierto, pero sí podía limitarle el control que tenía sobre sus fieles. Es de esta forma que el conflicto fue llevado a la Legislatura del Estado (Pennsylvania), para que de ella emanara una ley que le arrebatara la prerrogativa de nombrar a los sacerdotes en sus parroquias de la diócesis (cf. Billington, 1938: 40).

Sin dejar de hostigar a la bestia, ${ }^{7}$ los nativistas se organizan en asociaciones en donde debate acerca de la incompatibilidad del catolicismo con la democracia y sus beneficios. Convencidos de esto último, los nativistas de Nueva York organizan un debate titulado Is Popery compatible with Civil liberty? La actitud de la prensa converge con la de los nativistas al aprovechar la irrupción violenta de los católicos en el debate para arrojar luz, según esto, sobre otro de los razgos característicos del catolicismo: el de la intolerancia. "I be mobbed, declaró el orador interrumpudido, - -because I use the liberty guaranteed me by my country: the liberty of free discussión" (cf. Bellington, 1938: 58-62). 
Laidea de la superioridad cultural del protestantismo sobre el catolicismo se difunde entre quienes esperan que sea así. Boudon observa la tendencia en los individuos a ir más allá de la pura convicción en lo que se refiere a una opinión. El individuo rara vez se conforma con respaldar su opinión con hechos que observa o conoce. Por lo general, se muestra más o menos receptivo al saber que se manifiesta en torno a él. Pero esta necesidad se acrecenta cuanto los fenómenos aparecen ante la opinión pública como problemas de sociedad. Es entonces que los individuos resienten la necesidad de fundamentar su opinión en una buena argumentación. El debate responde de alguna manera a esta demanda. Se trata, pues, de un procedimiento cognoscitivo a través del cual se forman las creencias colectivas (Boudon, 1999).

Una creencia puede construirse a partir de conocimientos provenientes de la filosofía, de la teología o de la ciencia. De la filosofia política se sacaba la conclusión de la superioridad del régimen republicano sobre el monárquico. La restauración de la monarquía en Francia, y de una manera general la inestabilidad política que se abate sobre las monariquías de Europa en la época de Luis Felipe, fortalece esta idea. Ahora bien, los nativistas protestantes tomaban como un hecho la hostilidad de Europa hacia Estados Unidos por su adhesión a la república, régimen promovido por los adversarios de las monarquías existentes en Europa. Entre ellos se compartía la creencia de que a esta hostilidad se sumaba la del Vaticano, a quien por su estructura de poder se le percibía como parte integrante de un mismo sistema de alianzas. El papado, según este punto de vista, compartía con las monarquías de Europa no sólo la naturaleza despótica, autocrática, sino también la voluntad de actuar en contra de los Estados Unidos debido a su régimen democrático.

Es por ello que, de acuerdo a este punto de vista, el catolicismo americano defendía a la inmigración europea, percibida como una ola alentada por los países de Europa para romper con la homogeneidad cultural del país y la sensibilidad democrática.
En resumidas cuentas podríamos decir que de la catolicidad de los inmigrantes, la opinión estadounidense alcanzaba sólo a retener, y por asociación de ideas, una cierta relación de complicidad con el Vaticano. Pero no es sino hasta con la llegada en masa de los irlandeses católicos y luego de los europeos del Sur y del Este que surge el movimiento nativista y con ellos la difusión de la idea según la cual habría que preservar la homogeneidad angloprotestante de la sociedad estadounidense, y con tanto más urgencia, ya que de los bajos fondos de las ciudades industriales en donde se hacinaban los nuevos inmigrantes, surgían un cúmulo de problemas relacionados con la delincuencia, la criminalidad, el alcoholismo, la insalubridad. Para la opinión pública, y para la opinión publicada, como diría Michel Maffesoli al referirse a los productores de ideas (Maffesoli, 2009), la pobreza y la miseria humana de los inmigrantes no podía ser otra cosa que expresión social de individuos portadores de valores incompatibles con los que han hecho posible la democracia y la prosperidad del país (Morison y Steelle, 1951).

Los estadounidenses del siglo XIX se enorgullecían de haber hecho suyos los valores de los puritanos, los ideales gracias a los cuales el país prosperaba. El país se había diversificado en sus orígenes nacionales y pertenencias religiosas. Pero a pesar de ello, podían constatar que no había incompatibilidad cultural entre ellos, individuos portadores de culturas religiosas protestantes y la cultura puritana fundadora del país. La composición multidenominacional protestante de la sociedad y el auge industrial, como hechos observables, eran razonados en términos de causa y efecto y ello explica en buena medida el éxito del movimiento nativista en su combate para que se le diera preferencia a la inmigración europea de cultura protestante.

Aunque hay algo más decisivo, y que sin ello nunca hubiese pasado por justo el juicio de valor según el cual preservar la homogeneidad cultural del país es una buena cosa: es la utilidad, los beneficios, que su manipulación podría acarrearles a ciertas categorías sociales: clientela para los políticos, notoriedad para los periodistas e intelec- 
tuales, defensa del mercado religioso existente por parte de los protestantes, etcétera.

Se trata de una proposición que valdría la pena relativizar porque si bien hay utilidad, intereses por parte de los actores mencionados, tenemos que ver que hasta en los intereses es posible reconocer elementos de racionalidad axiológica. Si yo mismo me intereso más en esto que en aquello es porque valoro más esto que aquello. El interés, la percepción de loútil en las cosas y las elecciones de todo tipo, es pues también un valor, como lo observa Pierre Demeulenaere (2003: 22). Podríamos decir que sin racionalidad axiológica (evaluación de la argumentación en función de la conexión de un juicio factual con un juicio de valor), la preservación de la cultural WASP (blanca anglosajona y protestante) es una buena cosa porque con ello se garantiza el progreso económico del país. La idea no hubiese convencido a las categorías socioprofesionales citadas hace un instante, y aun menos la adhesión que genera en la clase trabajadora como ocurrió en 1843-1845, cuando el movimiento nativista desató la violencia en contra de los católicos, en esa época conformados en su mayoría por irlandeses y alemanes.

El lector podrá fácilmente percibir que nuestra concepción del individuo corresponde a la de un enteracional, sensible a los hechos como al cuerpo de conocimiento existente en el contexto en el que éste se mueve. En todo caso se trata de un axioma que nos ha parecido muy útil para comprender la lógica de los nativistas, preocupados por pulir la ideología del Anglo Conformity a la luz de las observaciones antropológicas aplicadas a los inmigrantes europeos originarios de Europa del Sur y del Este, que llegan en masa a los Estados Unidos a partir de 1880.

\section{Las diferencias culturales a la luz de la teoría socio- lógica: derivaciones ideológicas}

Tenemos que ver que la actitud del movimiento nativista con respecto a la inmigración se nutría de la literatura sociológica de la época y en particular de teóricos como
Francis Lieber, para quien la sociedad estadounidense debería de preservar la relación de afinidad que le venía de la historia a través del idioma, su comprensión de las leyes y los conceptos políticos, de sus recuerdos, de la religión y la economía doméstica. Para este teórico de la nación, era el entorno cultural que hacía posible el ejercicio de la libertad civil (cf. Ertel y et.al. 1979: 21, 22). Era, pues, del interés del país preservar su homogeneidad cultural [...] y de la humanidad también porque de esta condición dependía el sentido de "la misión sagrada de extender la libertad civil [...] en todos los puntos del globo" (Marienstras, 1976).

Raymond Boudon observa que las ciencias sociales son una de las principales fuentes de derivaciones, en el sentido que para bien o para mal las ideologías en busca de legitimación se inspiran de ellas. Bajo este mecanismo, las teorías pseudocientíficas, al igual que el razonamiento religioso, alcanzan a penetrar el conocimiento ordinario. Obsérvese, por ejemplo, la relación de parentesco existente entre la posición de Lieber y Franklin James Love, un misionero evangelista, con respecto a lo importante que era para la nación conservar la homogeneidad cultural en torno al idioma, la religión y la raza. Para el misionero evangelista, el alma era el vector de las cualidades humanas y, a su vez, dependía de la región y el idioma sin el cual sería imposible su difusión.

Para André Siegfried todo era cuestión de considerar el carácter problemático de la integración de los alemanes e ingleses católicos para probar que el problema radicaba en la cultura religiosa (cf. Anderson, 1970: 10).

Luego llegan al mercado de las ideas las teorías de tipo biogenético, demasiado seductoras como para no inspirarse de ellas. En efecto, el siglo XIX se había encargado de dar a luz al darwinismo social. Recordemos al conde de Gobineau con su obra La desigualdad de las razas, a Houston Stewart Chamberlain con su obra, por cierto ya olvidada, Fundaciones del siglo XIX y, en fin, los trabajos eugenésicos de Francis Galton, entre otros (cf. Peters, 1986: 118-121). Con estas nuevas herramientas de 
conocimiento, la ciencia intenta aclarar el problema de los contrastes en materia de desarrollo económico entre las diferentes civilizaciones del mundo.

Por supuesto que las ópticas bajo las que se percibía el mundo no eran las mismas en Europa que en Estados Unidos debido, precisamente, a las diferencias en los contextos (Anderson, 1970: 74). Dicho de otra manera, los estadounidenses, dada la realidad multicultural y sus esquemas explicativos, partían de un a priori más preciso que el de los europeos: el de la superioridad de la "civilización americana". En el laboratorio de la sociedad estadounidense, la tesis biogenética pasaba por el matiz de la evaluación no sólo a las razas sino también a la misma raza blanca en su diversidad. De esta manera, el carácter problemático de la integración de los inmigrantes finlandeses, por ejemplo, para no hablar de los mexicanos más tarde, fue entendido como un problema plausible de explicarse a la luz de este nuevo enfoque: racialmente identificados como asiáticos se les atribuía una cierta relación de consanguinidad con los mongoles (cf. Anderson, 1970: 74), el grupo racial con la más baja calificación de inferioridad.

Frente al carácter ineluctable de la inmigración proveniente de los países del Sur y del Este de Europa, los nativistas pensaban que con una ampliación del periodo de residencia como requisito para obtener la nacionalidad ( 21 años) bastaba para eliminar de la nacionalidad a los inmigrantes "incapaces de comprender los principios de la libertad civil y religiosa" (Billington, 1938: 204). Pero no es sino con la ley de inmigración de 1924 que, en los hechos, la legislación margina la inmigración proveniente de los países del Sur y del Este en beneficio de los europeos de cultura protestante (Anderson, 1970: 10,11). Con ello, el Congreso de la Unión cede ante un movimiento nativista convencido de la inferioridad moral y cultural genéticamente intrínseca a las razas latinas y eslavas (Morison y Steele, 1951).

La calidad moral de estos nuevos inmigrantes era tanto más dudosa que se les percibía como "miembros vencidos de razas vencidas" (Morison y Steele, 1951) y como una amenaza a las costumbres y los valores tradicionales de la sociedad estadounidense (Ertel y et. al, 1979: 27, 28), los que de una forma u otra habían garantizado desde los tiempos de las primeras colonias, la prosperidad del país. "¿Queremos que este país sea poblado por británicos, alemanes, escandinavos; históricamente libres, enérgicos, progresistas; o por eslavos y latinos, razas asiáticas, históricamente aplastados, atávico e inactivos?", observaba el Secretario de la Liga en favor de la Restricción a la Inmigración (Immigration Restriction League) (Anderson, 1970: 10).

\section{Conclusiones}

La retórica nacionalista sostiene que la democracia y la prosperidad del país fueron posibles gracias a los ideales y los valores que defendieron activamente los puritanos y sus herederos en espíritu, los protestantes de otras denominaciones. Para el nativismo ésta era una constante histórica que el país no debía perder de vista. Es por ello que pugnaban por que se considerara la preferencia protestante en materia de inmigración. Lo que sin duda alguna ayudó a que pasara por justo un juicio de valor así, es la utilidad, los beneficios egoístas ${ }^{8}$ que su manipulación prometía a ciertas categorías sociales. Aunque por otra parte, tenemos que decir que sin racionalidad cognoscitiva, tal y como lo hemos expuesto en el cuerpo de este trabajo, la idea no se hubiese difundido con tanta celeridad dentro de las filas de la clase obrera y el partido republicano, con ello se favoreció la tesis del movimiento nativista y las manifestaciones xenofóbicas en contra de los inmigrantes europeos de cultura católica.

Reymond Boudon (2003) observa que los pueblos creen en lo que creen porque tienen sus razones para creer en ello. Esto no excluye que las razones en las que se fundamentan tales creencias sean frágiles, dudosas o falsas. Lo importante aquí es que los actores suscriben a una idea cuando los datos de la realidad se imponen por su congruencia con las creencias a partir de las 
cuales estos mismos intentan explicarse los fenómenos. A partir de este principio es posible despejar la figura de un estadounidense medio particularmente sensible a las diferencias de raza, de cultura y de religión y a las argumentaciones emitidas por los productores de derivaciones ideológicas. Hablamos, pues, de un individuo que podía efectivamente constatar: a) que el país se desarrollaba, b) que el desarrollo había sido hasta entonces la obra de un pueblo en su mayoría protestante y de ascendencia anglosajona o integrada a ella, c) que el peso demográfico de la nueva inmigración de cultura católica crecía en importancia, y d) que el desempleo y la delincuencia afectaban de una manera notable a esta población. Ahora bien, la ciencia sugería, en ese entonces, que estos individuos eran portadores de una ética o moral dudosa y que ello era inexorable, lo cual podía bien explicar el carácter problemático de la nueva inmigración. Y todavía más, que el futuro del país peligraba ante el peso demográfico de una población portadora de cualidades morales inmutables de signo negativo. Asimismo, los expertos le hacen decir a la ciencia más de lo que ésta dice al respecto. Es el principio de la formación de núcleos de derivación ideológica, en el sentido de Pareto (1964).

De esta manera, lo que al principio no era más que una hipótesis de carácter heurístico, se convierte, al calor de la controversia, en una derivación ideológica en el sentido que la proposición, manejada por los políticos, pierde su carácter hipotético para ser considerada en el sentido real. " "El genio del productor consiste en convencer al demandante que es bien la autoridad que se expresa a través de su boca" (Boudon, 1999: 240).

El éxito mediático de la tesis de Samuel Huntington respecto al carácter problemático de la presencia de los latinos en los Estados Unidos, podría explicarse, en gran medida, a la luz de la proposición antes citada. Su tesis, lejos de ser concebida como una hipótesis, como un ejercicio heurístico, es tomada por un público alarmado ante el crecimiento galopante de la población latina en el Suroeste de los Estados Unidos como una realidad, como una amenaza real: la del surgimiento de una nueva nación de cultura hispana en el seno de los Estados Unidos, como consecuencia de su incapacidad para asimilar los valores sobre los que desde los tiempos de los primeros colonos se ha cimentado el crecimiento económico y moral del país. Es la ciencia que se expresa a través de la voz de Huntington.

\section{Notas}

'Sobre la noción paretiana de derivación, ver de una manera general la interpretación de Raymond Boudon (1998: 224, 225, 238, 261; 1999: 240).

${ }^{2}$ Nos referimos a la convicción como causa y al comportamiento como efecto. Se trata, pues, de un par de variables ordenadas en términos de causalidad racional, que es el axiomático bajo el cual opera el individualismo metodológico en su versión francesa propuesta por Raymond Boudon. Para un mejor conocimiento de este enfoque véase su texto Raisons, bonnes raisons, Paris: PUF, 2003.

${ }^{3}$ Con ello reconocemos implícitamente que las representaciones que afectan a los individuos son cristalizaciones de la realidad social (cf. Boudon, 2000: 120).

${ }^{4}$ Michel Maffesoli sostiene que el positivismo es una derivación cognoscitiva del monoteísmo, que de los monocausalismos religiosos a los mono-causalismos positivos no hay más que un paso.

${ }^{5}$ Respecto a la noción de actor típico ideal véase Arriaga (2008b).

${ }^{6}$ Como se podrá recordar, John F. Kennedy también tuvo que defenderse de tales sospechas durante su campaña como candidato a la presidencia.

7 "Postatre the beast" (cf. Bellington, 1938: 60).

${ }^{8}$ Entiéndase egoísmo como axiomático y no como un calificativo.

${ }^{9}$ Considérese la reflexión de R. Boudon (2000: 250-259) para lo relacionado con el concepto paretiano de derivación ideológica y su relación entre conocimiento científico e ideología. 
INMIGRACIÓN Y DISCRIMINACIÓN: MECANISMOS SOCIOCOGNOSCITIVOS

\section{Bibliografía}

Anderson H. Charles (1970), White protestants américains. From national origins to religious group. New Jerse: Prentice-hall, Inc. Engleood Cliffs.

Arriaga, Martínez, Rafael (2008), Religion, groupes éth niques et processus de stratification sociale aux Etats Unis: le cas des mexicains-américains d'une perspective comparative. Tesis de doctorado, Paris: Universidad de Sorbonne, pp. 562.

Arriaga Martínez, Rafael (2008b), "Religión, grupos étnicos y procesos de estratificación social en los Estados Unidos: el caso de los mexicanos y chinos desde una perspectiva comparativa", en Estudios Fronterizos, enero-junio, vol. 9, núm. 17, pp. 107-147.

Arriaga, Martínez, Rafael (2009), "Dios y Estados Unidos: teología e ideología del destino nacional", en Sandez, Agustín y otros (coords.), Estudios fronterizos: migración, sociedad y género, México: Ed. UABC, pp. 45 66.

Baltzell E. Digby (1979), Puritan Boston and Quaker Philadelphie. Two protestant Ethics and the spirit of class authority and leadership, New York: The Free Press,

Billington, Ray Allen (1938), The protestant Crusade 18001860. A Study of the Origins of American Nativism. New York: The MacMillan Company.

Boudon, Raymond (1998), Etudes sur les sociologues classiques, Quadrige, Paris: Presse Universitaire de France.

Boudon, Raymond (1999), Le sens des valeurs, Quadrige, Paris: Presse Universitaire de France.

Boudon, Raymond (2000), Etudes sur les sociologues classiques II, Quadrige, Paris: Editions Presse Universitaire de France.

Boudon, Raymond (2003), Raison, bonnes raisons, Paris: PUF. Boudon, Raymond (2007), Essais sur la théorie générale de la rationalité, Paris: PUF.

Bureau of the Census, (1970), "International migration and Naturalization", en Historical Statistics of the Uni- ted States. Colonial times to 1970, Washington: U.S. Department of Comerce.

Demeulenaere, Pierre (2003), Les normes sociales. Entre accords et désaccords, Paris: PUF.

Ertel, Rachel, Fabre, Généviève y Marienstras, Elise (1979), Sur les minorités des Etats Unis, Paris: Editions F. Maspero.

Gallup Organization (2005), Religion "very Important" to most americans, Princeton: Łhttp:/www.gallup.com/ poll/20539/Religion-very-important-Most-Americans.aspx> [12 de Octubre de 2006].

Gallup Organization (2007), Just whay do americans attend church?, Princeton: 〈http:/www.gallup.com/ poll/27124/Just-Whay-Americans-Attend-Church. aspx> [5 de noviembre 2008].

Hsiang, Shui Chen (1992), Chinatown no more: Tä̈wan immigrants in contemporary New York, New York: Cornelle University Press.

lnglehart R., Basanez M., Moreno A. (1998), Human Values and Beliefs: A Cross-Cultural Sourcebook, Ann Arbor: The University of Michigan Press.

Maffesoli, Michel (2009), Apocalypse, Paris: Editions CNRS.

Marienstras Elise (1976), Les myths fondateurs de la nation américaine, Paris: François Maspero.

Morison Samuel y Commager Steelle (1951), Historia de los Estados Unidos de Norteamerica, tomo II, México: F.C.E.

Pareto, Vilfredo (1964), "Traité de Sociologie Générale”, en Euvre complète, Genève, Droz.

Peters, Georges (1986), Tentatives scientifiques de justifier la discrimination raciale. Science et racisme, Publications de l'Université de Lausanne, Cours General Publique 1985-86, Editions Payot Lausanne.

Weber, Max (1959), Le savant et le politique, Paris: Editions Plon.

Weber, Max (1967), L'hetique protestante et l'esprit du capitalisme, 2a. edición, Paris: Editions. Plon. 